\title{
DELITO, DETENÇÃO E ENCARCERAMENTO - O APRENDIZADO DE UMA ATIVIDADE LABORATIVA COMO INSTRUMENTO DE RESSOCIALIZAÇÃO DE MENORES EM CUMPRIMENTO DE MEDIDAS SOCIOEDUCATIVAS
}

\author{
Marta Cruz Machado ${ }^{1}$
}

\begin{abstract}
RESUMO
O presente trabalho discutirá a ressocialização de menores cumpridores de medidas sócioeducativas, internos do CASE - Instituto Juiz Melo Matos em Feira de Santana, através do aprendizado de uma atividade laborativa ou profissionalizante. A casa de Atendimento sócio-educativo Juiz Melo Matos é uma instituição pública mantida pela FUNDAC/BA (Fundação Estadual da Criança e do Adolescente do Estado da Bahia) entidade responsável por formular e executar uma política uniforme de proteção aos direitos da criança e do adolescente. Na busca de ratificar ou refutar a hipótese levantada, será realizado um extenso estudo de referencial teórico, que verse a respeito do tema, e uma pesquisa por meio da aplicação de questionário aos internos, traçando o perfil desse indivíduo, bem como sua condição na prática do ato infracional; em seguida, será analisada a predisposição para o aprendizado de uma atividade laborativa e seu desejo de ressocialização. Será aplicado ainda um questionário aos funcionários do instituto, que emitirão suas impressões sobre os internos nos momentos de desenvolvimento dessas atividades. E por último proceder-se-á com a leitura, tratamento e análise dos dados coletados.
\end{abstract}

Palavras-Chave: Menor infrator. Melo Matos. Ressocialização de menores. Medidas socioeducativas. Profissionalização.

\section{INTRODUÇÃO}

O artigo constitui-se no resultado do estudo desenvolvido em função do projeto A utilização de alimentos descartados como instrumento de ressocialização dos internos do CASE -Instituto Juiz Melo Matos. Através de dados recolhidos na secretaria de segurança pública da cidade de Feira de Santana / BA e de pesquisa em setores ligados a esse órgão, bem como a pesquisa in loco, fica exposta também, através de números, a real situação da problemática de detenção, encarceramento e

\footnotetext{
${ }^{1}$ Graduanda em Direito pela Faculdade Nobre de Feira de Santana (FAN), Pós-Graduanda em Filosofia pela Universidade Estadual de Feira de Santana (UEFS), Especialista em Gestão Estratégica e Negócios pela Universidade do Estado da Bahia (UNEB), Bacharel em Administração pela Universidade Salvador. E-mail: maitecruz.cruz@hotmail.com.
} 
ressocialização de jovens da cidade de Feira de Santana/BA, com a intenção de contextualizar e fornecer dados para uma melhor compreensão do nosso objetivo principal que é analisar a real possibilidade de ressocialização dos internos da CASE Instituto Juiz Melo Matos. Construiremos um panorama da Cidade e dos órgãos no que se refere ao judiciário e seus apêndices sobre a ressocialização de menores em Feira de Santana.

Feira de Santana é um município brasileiro do Estado da Bahia, situado a 108 quilômetros de sua capital, Salvador, a qual se liga através da BR-324, que apesar de estar localizada no agreste baiano é conhecida como a Princesa do Sertão. Destaca-se por possuir o maior entroncamento rodoviário do Norte-Nordeste, com população estimada de 617.528 habitantes, os dados são do Instituto Brasileiro de Geografia e Estatística (IBGE) - Diretoria de Pesquisas (DPE) - Coordenação de População e Indicadores Sociais (COPIS), que divulgou a estimativa da População residente 2011-2015, tendo população flutuante de um milhão de pessoas, denominada pelo IBGE como a única Cidade grande do interior do Norte, Nordeste e Centro Oeste do país. Cidade essencialmente comercial, com destaque também para agricultura e indústria.

Com relação aos órgãos que conduzem questões referentes a criança e ao adolescente em conflito com a lei, a cidade possui uma vara da infância e da juventude, uma promotoria da vara da infância e juventude e a Delegacia para o Adolescente Infrator - DAÍ. Esses órgãos mantêm estreita relação e integração entre si o que possibilita uma maior agilidade na resolução das questões. Entretanto possui apenas uma unidade de atendimento ao adolescente praticante de atos infracionais e que esteja em privação de liberdade, que é o CASE - Juiz Melo Matos mantida pela FUNDAC, sendo a primeira unidade de internação da FUNDAC/BA a ser concebida atendendo à regionalização do atendimento, prevista pelo Estatuto da Criança e do Adolescente (Lei no 8.069, de 1990).

Quando pensamos o cerceamento da liberdade, remetemos imediatamente, a tempos remotos, às prisões e aos terríveis castigos e suplícios através dos quais eram aplicadas as penas, mas o direito penal da época defende-se afirmando que o suplício é uma técnica inexplicável para os dias atuais, mas certamente não era irregular nem selvagem, baseava-se na aplicação quantitativa e gradativa do sofrimento, quanto maior o grau do delito mais severa, humilhante e marcante deveria ser o suplício, marcante não apenas no sentido psicológico para aquele que o recebia, mas também para aquele que assistia, bem como deveria produzir no detento marcas físicas inesquecíveis e irreparáveis. É nesse momento que o suplício mostra a sua verdadeira face de apartamento 
social, quando impede, através das marcas, que aquele que cometeu um delito, mesmo que de gravidade discutível e após ter sanado a sua suposta divida social, esteja impedido de retornar ao convívio social. O suplício deve ser humilhante, torna infame aquele que é sua vítima, tem como função purgar o crime, e não reconciliar, é um ritual organizado para a marcação irreparável das vítimas, ostentação e glorificação do poder que a pune. Numa visão caracteristicamente Lombrosiana $^{2}$ seria inútil penar em reparação de indivíduo que possui o crime arraigado na sua espinha dorsal.

\section{METODOLOGIA}

A metodologia aplicada para o desenvolvimento da presente pesquisa foi efetivada em quatro etapas, a primeira consta de uma pesquisa bibliográfica contemplando diversos autores que pesquisam a ressocialização, dando uma atenção especial para a ressocialização de menores, através da aprendizagem de uma atividade laborativa para que possam, egressos, manter uma atividade profissional regular, que atenda as suas necessidades básicas mais urgentes, sem que para isso o menor tenha que cometer ações que conflitem com a lei. A segunda etapa desenvolveu-se uma pesquisa em arquivos junto a CASE - Instituto Juiz Melo Matos, com o objetivo de identificar através de um estudo minucioso dos documentos a mudança ou a falta dela na personalidade do menor que passou ou está passando por oficinas profissionalizantes. A terceira etapa referiu-se em um questionário composto por trinta e seis perguntas, aplicado a 21 dos 42 menores internados no Instituto, no período de 23 de março à 22 de abril de 2010, quando a pesquisadora buscou identificar os desejos e aspirações dos sujeitos

\footnotetext{
${ }^{2}$ Cesare Lombroso, italiano nascido no sec. XIX atua em variadas áreas de conhecimento, como medicina, psiquiatria, antropologia e política, foi um importante escritor nas diversas áreas em que atua, contudo foi por seus escritos em Criminologia que lembrado ate aos dias atuais. Sua concepção positivista acerca do indivíduo delituoso, baseado em autores como Darwin o levaram a relacionar certos aspectos físicos possuídos por esses indivíduos com a prática de delitos. Em seus estudos atribuiu à hereditariedade quase que completa culpa pelos atos praticados pelo delinquente. O individuo criminoso seria um delinquente nato (nascido para o crime), criminoso desde antes do seu nascimento, um ser geneticamente degenerado, defeituoso, atávico (onde a espécie humana involui, regride), marcado pela transmissão hereditária do mal. Essa delinquência esteticamente perceptível para o autor seria demonstrada por uma série de características, estigmas degenerativos, comportamentais, psicológicos e sociais no seu ponto de vista. A pessoa não seria influenciada pelo meio, as influências externas em pouco iriam contribuir, pois a patologia criminosa já se encontrava nele, era questão de tempo até que essas características ganhassem vasão. Apesar de ter ganhado grande notoriedade nos anos posteriores a sua publicação, suas teses foram gradativamente perdendo espaço de aplicação, contudo academicamente ainda são repetidamente trazidas à tona como modo de explicar práticas sociais que em muito já deveriam ter sido abolidas. $\mathrm{O}$ autor determinou seis tipos de criminosos: $\mathrm{O}$ nato, o louco moral, o epiléptico, o louco, o ocasional e o passional. No entanto, as características encontradas por Lombroso eram basicamente do negro, imigrante na Itália. A tal "face" criada pelo autor se confundia com a figura afro, fato que tachou sua tese como racista.
} 
pertencentes à amostra em análise. A aplicação do questionário deparou-se com limitações devido a problemas como o alto grau de periculosidade de alguns internos que colocaria em risco a integridade física do entrevistador, bem como a recusa de outros internos em responder o questionário, o que impossibilitou a aplicação a $100 \%$ da população em estudo. A quarta e última etapa, constou da aplicação de uma entrevista semiestruturada para coleta de dados primários junto aos profissionais que trabalham diretamente com os menores internos na CASE - Instituto Juiz Melo Matos.

\subsection{Análise estatística}

Após o processamento dos dados no programa estatístico SPSSWin, foram realizadas as análises exploratória dos dados levantados. Estas análises consistiram na elaboração de tabelas de frequência (absoluta e percentual) no Word, mediante os outputs gerados pelo pacote SPSSWIN sobre o perfil socioeconômico, demográfico e experiência profissional dos internos, bem como dos determinantes que levaram estes a situação de internamento. Além de se estudar a distribuição das perspectivas e estrutura de apoio fornecida pela institucional pesquisada, geram-se também gráficos (coluna/barra e setor) com o objetivo de destacar os principais achados deste levantamento (TRIOLA, 1999).

\section{A PENA AO LONGO DA HISTÓRIA}

Até o século XVIII, em grande parte dos países europeus, o processo criminal até a sentença permanecia secreto tanto para o público quanto para o acusado. É negado ao suplício a categoria de reparação do ao supliciado "a severidade da época precedente, era impossível ao acusado ter acesso às peças do processo, impossível conhecer a identidade dos denunciadores, impossível saber o sentido dos depoimentos antes de recusar as testemunhas, impossível fazer valer, até os últimos momentos do processo, os fatos justificativos, impossível ter um advogado, seja para verificar a regularidade do processo, seja para participar da defesa" (FOUCAULT, 2009, p. 37).Bem como era negado ao supliciado o direito de se defender, chegava-se a afirmar que aquele sobre o qual recaísse uma acusação, não poderia ser completamente inocente, os

julgamentos possuíam características estritamente inquisitoriais. Presumia-se a culpabilidade do indivíduo desde a sua acusação, que deveria por seus próprios esforços, sob as condições mais adversas e desfavoráveis provar a sua inocência. Ainda para o autor 
o direito a defesa trazia ao homem muito mais que a garantia de vida, trazia também a garantia de humanidade.

A defesa da própria existência é a lei suprema de toda vida: manifesta-se em todas as criaturas por meio do instinto de auto conservação. No homem, porém, trata-se não apenas da vida física, mas também da existência moral; e uma das condições desta é a defesa do direito. No direito o homem encontra e defende suas condições de subsistência moral; sem o direito, regride a condição animalesca, tanto que os romanos, numa coerência perfeita, colocavam os escravos no mesmo nível dos animais, do ponto de vista do direito abstrato. (IHERING,2002, p.20).

Na segunda metade do século XVIII, apareceram os reformadores que perceberam que a execução da forma como ocorria, no final das contas simplesmente não assustava o povo; esses rituais ambíguos foram suspensos em alguns países e em grande parte desses já no século XVIII. Esta suspensão não representava, contudo, um sentimento de humanidade para com os condenados, mas sim, uma medida de autopreservação por parte do poder judicial, temendo despertar o repúdio e a ira da população.

Entretanto, quando a força limitada do indivíduo se debate em vão contra certas instituições que ofereçam ao árbitro antijurídico um sustentáculo que é negado do direito, nesse caso a tormenta volta-se contra quem a desencadeou: o destino que aguarda esse indivíduo será o do crime que infringiu a lei por causa do sentimento de justiça ofendido[...]. (IBIDEM, p. 29).

No final do século XVIII e início do século XIX, os protestos contra os suplícios, as condenações excessivas e a pena de morte se tornaram cada vez mais frequentes e eram vistos em todos os níveis e classes sociais. "É preciso punir de outro modo[...]"(FOUCALT, 2009, p. 71).O suplício tornou-se rapidamente intolerável em sentido amplo, e para todas as classes, nesse, ninguém encontra apoio, lugar no qual possa se bem dizer ou apoiar-se, “o suplício tornou-se rapidamente intolerável. Revoltante, visto da perspectiva do povo, onde ele revela a tirania, o excesso e a sede de vingança"(IBIDEM, p. 72). Os reformadores denunciavam o excesso que configuravam o exercício ilegítimo do poder tanto de um lado quanto do outro, nesse momento é preciso punir ao invés de se vingar.

As reformas do século XVIII lançaram luz sobre o ato do castigo que deve ter a humanidade como medida (economia dos castigos). "Que as penas sejam moderadas e 
proporcionais aos delitos, que a de morte só seja imputada contra os culpados assassinos, e sejam abolidos os suplícios que revoltem a humanidade." (SELLIGMAN, 1901, t. 1).

Um pouco mais adiante surge o momento de transição, quando o castigo deixa de ser uma agressão física insuportável para se tornar uma economia ou suspensão dos direitos (liberdade), o corpo deixa de ser instrumento de castigo através do suplício, a pena busca nesse momento algo que vai além da punição do corpo físico, isso ocorre não somente por entenderem os responsáveis por delegá-las, a sua ineficácia ou amoralidade, mas também por buscarem os magistrados a libertação de tão indigno ofício.

O poder judiciário apresenta o seu oposto extremo no momento em que encarrega a um médico ou profissional da área de saúde que acompanhe o condenado à morte, zelando por seu bem estar até o último momento, buscando dar a este condenado uma morte isenta de dor, o desligamento e a suspensão de todos os seus direitos físicos (existir), mas sem o suplício, uma punição que atinja mais a vida que o corpo (um castigo incorpóreo). Este novo modo de ver e aplicar a punição evidencia uma nova moral no ato de punir (enclausurado, não castigado), no qual o espetáculo foi extinto, mas não o ato em si, em verdade a morte penal através dos suplícios do corpo permanece hoje ainda, veladamente, nos porões das prisões, como se não existissem, ou na posição de pretensos atos comuns inerentes ao sistema penal, um ato que com inteira justiça para evitar mais iniquidade deve ser revisto.

A pena que nesse momento já não visa o corpo, talvez tenha sua intensidade reduzida, mas certamente o que mudou mesmo foi o foco de aplicação, que agora se volta para a alma, atingindo impiedosamente o coração, o intelecto, a vontade, as disposições. A justiça precisa lidar agora com uma realidade incorpórea, e nesta, as definições das infrações foram alteradas sem perder, é claro, a divisão de permitido e proibido, entretanto, o crime objeto da prática penal foi profundamente modificado, o julgamento dos delitos continua rigidamente definido pelo código, porém agora são considerados os impulsos e desejos, busca-se com isso verificar até que ponto a vontade do réu estava envolvida no crime e para isso são utilizados elementos circunstanciais juridicamente não codificáveis. A antropologia criminal o discurso repisante da criminologia vem dar aos processos de punição legal um poder justificável sobre os indivíduos e não mais apenas sobre as infrações, não mais sobre o que eles fizeram, mas sobre aquilo que eles são, serão ou possam ser.

Essa nova modalidade judicial do julgamento tem caráter anexionista e não substitutivo, foi se instaurando lenta e dificilmente, todavia, sem estagnar as 
transformações foram se tornando cada vez mais visíveis, julgar não era mais apenas verificar a verdade de um crime, determinar seu autor e aplicar-lhe uma pena legal, agora suas variáveis deveriam ser levadas em consideração, elencar questionamentos que pudessem explicar o significado do fato, da violência e do crime, seu grau de periculosidade, as causas que o produziram, identificar no autor a origem do crime, que medida é mais apropriada, como prever a evolução desse criminoso e principalmente qual medida é mais eficiente para corrigi-lo "o essencial da pena [...] não creiais que consista em punir; o essencial é procurar corrigir, reeducar, "curar" [...]”. (FOUCAULT, 2009, p.05).

É importante frisar que a palavra ressocialização ainda não é vista como objetivo, no entanto vale ressaltar que neste momento o sistema de juízo penal colhe uma nova verdade que vem modificar de forma irreversível a mecânica judicial existente. Esta não possui mais a prerrogativa apenas de punir, o juiz não carrega mais consigo a alcunha de castigador; é visto então como mecanismo indispensável no caminho da cura, faz parte de um grupo significativo de ações, a reclusão agora sem o castigo, não é mais medida única, mesmo indispensável, faz parte do novo modo de exercício da justiça criminal uma nova justiça que une técnica e ciência no caminho da recuperação.

\subsection{Modelos das penas}

Os tipos de penas privativas de liberdade são três: o retributivo, o reabilitador e o restaurador. Cuja diversidade refere-se igualmente aos diversos aspectos do crime cometido.

No sistema retributivo, a pena é simplesmente um castigo imposto a quem praticou um crime. Tendo caráter apenas de privação, de liberdade esta não busca recuperar, nem reintegrar o infrator.

Para o sistema reabilitador ou ressocializador, a pena deve ser uma medida ressocializadora. Neste sistema a prisão, bem como a privação de liberdade configura-se como um local e um tempo, uma "quarentena social" onde o apenado possa se ressocializar.

No sistema reparador, a pena objetiva reparar o dano sofrido pela vítima. Esse tipo de pena visa, além de reparar o dano da vítima, ressocializar o infrator, prevenindo futuros delitos. Nesse sistema, as penas alternativas destacam-se como a opção mais efetiva, pois, comungam com os dois objetivos. 
Após as reformas de 1984 e 1998 o Código Penal Brasileiro, passou a adotar um sistema misto, o retributivo-preventivo. Entretanto são raras as instituições que conseguem na prática a implementação dessas reformas, em sua maioria, as prisões continuam a serem cárceres para indivíduos que antes carrascos, passam a vítimas de um sistema prisional ineficaz e castigador.

\section{FEIRA DE SANTANA}

Na Delegacia para o Adolescente Infrator de Feira de Santana/BA,desde 2001, ano de sua criação até 2007 foram registradas 8.756 (oito mil, setecentos e cinquenta e seis) ocorrências, das quais 3.296 (três mil, duzentos e noventa e seis) boletins circunstanciados instaurados e remetidos envolvendo menores, sendo que os registros de homicídios, considerados ocorrência de maior gravidade foram 45 (quarenta e cinco) o que representam $0,51 \%$ do total de todas as ocorrências, desses casos, apenas $5,71 \%$ dos menores são encaminhados para o Centro de Atendimento ao Menor (CAM) - Salvador, instituição que fica na capital do estado a 107 km de Feira de Santana,nos demais 94,29\% dos casos, os menores que cometem esse delito são encaminhados ao CASE - Juiz Melo Matos atendendo sempre a determinação da vara da infância e da juventude que é responsável por julgar o delito e decidir o destino do menor.As decisões primam por respeitar à determinação de regionalização do atendimento, prevista pelo Estatuto da Criança e do Adolescente (Lei nº 8.069, de 1990), entendendo que essa regionalização aproxima os internos de suas famílias e favorece a sua reintegração social. (Dados coletados junto a Delegacia para o Adolescente Infrator, Feira de Santana /BA, 2010).

\subsection{O LOCUS DA PESQUISA EMPÍRICA}

O CASE - Instituto Juiz Melo Matos é uma unidade de ressocialiazação de menores do sexo masculino cumpridores de medidas sócio-educativas mantido pela FUNDAC - Fundação Estadual da Criança e do Adolescente do estado da Bahia, fíca localizado a Rua: Rua Artêmia Pires Freitas, s/n, Bairro: Sim, CEP.: 44085-370, Feira de Santana - BA. Tem capacidade para abrigar 65 internos, a unidade é a única na cidade destinada a esse fim, abriga internos de Feira de Santana e outras cidades, foi criada no dia 20/01/1998, sendo assim completou 12 anos no dia 20/01/2010, ao longo desse tempo abrigou mais de 2.200 jovens. 
A unidade possui um trânsito significativo de internos (novos e reincidentes), atualmente a unidade que tem capacidade para 65 (sessenta e cinco) menores, abriga 42 (quarenta e dois) internos em idade entre 13 (treze) e 17 (dezessete) anos sendo que a maior incidência é de indivíduos com 16 (dezesseis) e 17 (dezessete) anos, segundo a coordenadora técnica da unidade, muitos desses jovens infelizmente já passaram pela instituição diversas vezes demonstrando assim sua incapacidade de ressocialização desse indivíduo, todos os jovens que passam pela unidade são avaliados pela equipe técnica do instituto (assistente social, psicólogo, terapeuta ocupacional, advogado, pedagogo, professores, instrutores, médico, dentista, enfermeira, segurança interna) dessa avaliação é extraído um parecer técnico que é encaminhado para apreciação e decisão judicial sobre o destino do interno, no caso de medida de internação por tempo de permanência superior a seis meses, a avaliação é refeita no sexto mês, para avaliar a possibilidade de liberação dos internos nesse segundo parecer também o interno e seus familiares são ouvidos, contribuindo assim para que a melhor decisão seja tomada, e estando as partes envolvidas no acordo, todos possam trabalhar juntos.

Para os jovens que são submetidos à medida de internação é estabelecida uma rotina de estudos. Desde 2002 eles são matriculados numa escola regular (Colégio Estadual João Paulo VI) coma única diferença que são os professores que vão até eles, as aulas são ministradas nas dependências da instituição no período matutino, à tarde os internos estão livres para participar de cursos de iniciação a: serigrafia, informática, teatro, artes plásticas, música, também é oferecida a possibilidade da prática de alguns esportes.

Os internos possuem dois encontros semanais com os familiares que assim como numa instituição regular de ensino, algumas famílias tomam para si a responsabilidade acerca da conduta do menor, outras entregam ao estado através da instituição à responsabilidade sobre quaisquer atos cometidos pelos menores, bem como a sua recuperação social. Contudo, sem a família e sem uma perspectiva (sonhos), esses jovens distanciam-se cada vez mais da possibilidade de ressocialização, tornando cada vez mais arraigado o desvio de caráter que é expresso através da violência entre os próprios menores, e das rebeliões, que apesar do instituto não possuir dados específicos, giram em torno de 20 (vinte), número significativamente alto se imaginarmos que o índice aproxima-se de duas rebeliões por ano, e que na última rebelião um interno foi friamente assassinado por outro. Contudo a questão que gera inquietação tanto a este artigo quanto aos gestores da instituição não é apenas o período de manutenção desse menor enquanto 
interno, o que deve ser visto como questão superior é o momento que esse egresso e abandonado à própria sorte numa sociedade muito semelhante, ou ainda pior que a presente no momento de sua internação, pois, nesse momento, o menor que busca se reinserir no contexto social muitas vezes não possui contato nem vínculos com a sociedade, carrega o estigma de ser um ex-interno de uma instituição do sistema prisional e para o seu completo desespero não possui função social clara, e, sem capacitação profissional, certamente não terá como se sustentar até aprender a fazer algo lícito que possa the gerar subsistência. Sem ajuda e sem profissão o caminho que resta a esse egresso é a reincidência na prática de atos ilícitos que, na melhor das hipóteses, lhe levará de volta ao instituto para ressocialização de menor, pois quando esse atingir a maioridade certamente engrossará a massa que superlotam as penitenciárias, vivendo em condições sub-humanas e convivendo com criminosos de alta periculosidade de quem somente aprenderá atos da pior estirpe.

\section{O PROBLEMA DE PESQUISA}

Esta pesquisa científica traz à superfície das inquietações, reflexões iniciais, mas não superficiais, sobre a forma com que Estado e Sociedade tratam a profissionalização dos jovens internos de instituições de privação de liberdade, questão essencial para a ressocialização dos mesmos, identificando ainda a distância entre o que se pretende com o projeto para esse grupo social e o que se efetiva no cotidiano, bem como uma apreciação minuciosa das referências bibliográficas sobre o tema.

Ao propor a ressocialização, através da profissionalização, o projeto afina-se com o Estatuto da Criança e do Adolescente (1990), que propõe:

Art. 68. O programa social que tenha por base o trabalho educativo, sob responsabilidade de entidade governamental ou não-governamental sem fins lucrativos, deverá assegurar ao adolescente que dele participe condições de capacitação para o exercício de atividade regular remunerada.

$\S 1$ Entende-se por trabalho educativo a atividade laboral em que as exigências pedagógicas relativas ao desenvolvimento pessoal e social do educando prevalecem sobre o aspecto produtivo.

§ 20 A remuneração que o adolescente recebe pelo trabalho efetuado ou a participação na venda dos produtos de seu trabalho não desfigura o caráter educativo. 
Art. 69. O adolescente tem direito à profissionalização e à proteção no trabalho, observados os seguintes aspectos, entre outros:

I - respeito à condição peculiar de pessoa em desenvolvimento;

II - capacitação profissional adequada ao mercado de trabalho. [...].

Sua prática baseia-se no respeito à dignidade desse jovem, estimulando-o a desenvolver suas potencialidades, fortalecer seus vínculos familiares e resgatar sua condição de sujeito de direitos.

Em entrevista com a titular da Delegacia para o Adolescente Infrator de Feira de Santana, fica evidente a sua crença na ressocialização através do trabalho, desses jovens com os quais ela lida diariamente. Dorean dos Reis Soares (informação verbal, 2010, $58 \mathrm{~min}$.)

O caminho é esse, apenas através da supressão da vadiagem, com o trabalho é possível recuperar o menor, mas que isso se aplique também a família, para que ao sair do regime de privação de liberdade, o menor encontre um meio que possa o acolher, de modo que o possibilite a ter equilíbrio e mecanismos para reintegração social, realidade bem diferente do cotidiano de pobreza e miséria normalmente encontrada por esses jovens. (DOREAN SOARES, 2010).

Nas palavras da delegada, responsável por ter o primeiro contato com o menor infrator após a apreensão, podemos notar que o problema é muito mais social que legal, ficando explícita a carência de apoio socioeducativo e familiar, onde hoje impera a força policial e um senso de legalidade estrito, que não analisando detalhadamente $o$ caso concreto, apenas corrobora para a estratificação da marginalidade.

\section{RESULTADOS ALCANÇADOS}

Neste item serão apresentados e analisados os resultados da pesquisa empírica realizada no período de 23 de março a 22 de abril de 2010.

Quadro 1 - Perfil do Interno

\begin{tabular}{|l|l|l|}
\hline Variável & $\mathbf{N}$ & $\mathbf{\%}$ \\
\hline Idade (anos) & & \\
\hline 14 a 15 anos & 04 & 19,0 \\
\hline 16 a 17 anos & 11 & 52,4 \\
\hline
\end{tabular}




\begin{tabular}{|l|l|l|}
\hline 18 a 20 anos & 06 & 28,8 \\
\hline Onde você nasceu? & & \\
\hline Feira de Santana & 08 & 38,1 \\
\hline Outros $^{3}$ & 13 & 61,9 \\
\hline Estado civil? & & \\
\hline Solteiro & 18 & 85,7 \\
\hline Tem companheiro & 03 & 14,3 \\
\hline Têm filhos? & & \\
\hline Sim & 05 & 23,8 \\
\hline Não & 16 & 76,2 \\
\hline Religião? & & \\
\hline Evangélico / Protestante & 08 & 38,1 \\
\hline Católico & 06 & 28,6 \\
\hline Não possui & 07 & 33,3 \\
\hline Grau de escolaridade? & & \\
\hline Analfabeto & 03 & 14,3 \\
\hline $1^{\circ}$ Grau incompleto & 18 & 85,7 \\
\hline Cor? & 16 & 76,2 \\
\hline Parda & 05 & 23,8 \\
\hline Preta & & \\
\hline & & \\
\hline
\end{tabular}

Fonte: Pesquisa de campo realizada em 23 de março a 22 de abril de 2010.

Através dos dados expostos na Tabela 1, é possível traçar o perfil do menor interno do CASE - Instituto Juiz Melo Matos. Esse indivíduo identificado pela pesquisa está prestes a atingir a maioridade, pois em sua maioria 52,4\% possui entre 16 e 17 anos, verificou-se que $28,8 \%$ da amostra é composta por indivíduos com faixa etária entre 18 e 20 anos. Apenas 38,1\% da amostra é originária da cidade de Feira de Santana. Verificouse ainda que $85,7 \%$ dos menores pertencentes à amostra são solteiros, $76,2 \%$ não possuem filhos, e $75,7 \%$ possui o primeiro grau incompleto, a cor da pele em sua totalidade $100 \%$, é formada por pardos e pretos, porém o IBGE determina que a cor parda e a cor preta formam o grupo étnico de negros.

\footnotetext{
${ }^{3}$ Conceição do Jacuípe - BA, Santo Antonio de Jesus - BA, São Gonçalo - BA, Serrinha - BA, Santo André
} - SP, Paragominas - MG. 
Quadro 2 - Estrutura Familiar

\begin{tabular}{|l|l|l|}
\hline Variável & N & $\%$ \\
\hline Qual o estado civil dos seus pais? & 05 & 23,8 \\
\hline Moram juntos ${ }^{4}$ & 16 & 76,2 \\
\hline Separados & 18 & 85,7 \\
\hline $\begin{array}{l}\text { Você morava com familiares no momento em que cometera o suporto delito que } \\
\text { culminou em sua internação? }\end{array}$ & 03 & 14,3 \\
\hline Sim & 18 & 85,7 \\
\hline Não & 03 & 14,3 \\
\hline Voltará a morar com seus familiares no momento em que recuperar a liberdade? \\
\hline Sim & 18 & 76,2 \\
\hline Não & 16 & 23,8 \\
\hline Qual a renda (Salário Mínimo) da sua família no momento de sua internação? \\
\hline <1 SM & 05 & 2010, \\
\hline 1-2 SM &
\end{tabular}

Fonte: Pesquisa de campo realizada em 23 de março a 22 de abril de 2010.

$\mathrm{Na}$ Tabela 2, podemos verificar a estrutura familiar do entrevistado, na qual $76,2 \%$ dessas famílias possuem estrutura nuclear, e $85,7 \%$ desses indivíduos residiam com a família no momento em que cometeu o ato de infração, o mesmo percentual $(85,7 \%)$ pretende regressar ao núcleo familiar no momento em que recuperar a liberdade. Podemos identificar outro fato mitigador desse desejo de ressocialização, 76,2\% das famílias dos indivíduos entrevistados possuem renda inferior a 01 salário mínimo.

Quadro 3 - Fatores Determinantes

\begin{tabular}{|l|l|l|}
\hline Variável & N & $\%$ \\
\hline O que motivou sua internação no Instituto Juiz Melo Matos? & \multicolumn{2}{|l|}{} \\
\hline Assalto & 09 & 42,9 \\
\hline Tráfico de tóxico & 03 & 14,3 \\
\hline Assassinato & 05 & 23,8 \\
\hline
\end{tabular}

\footnotetext{
${ }^{4}$ Para melhor compreensão e aplicação do questionário não foram feitas distinções entre os diversos tipos
} famílias ou agrupamentos familiares. 


\begin{tabular}{|l|l|l|}
\hline Outros $^{5}$ & 04 & 19,0 \\
\hline Você é reincidente? & 11 & 52,4 \\
\hline Sim & 10 & 47,6 \\
\hline Não & \multicolumn{2}{|l|}{} \\
\hline $\begin{array}{l}\text { Ao longo de sua vida, quanto tempo já passou recluso em instituições de privação de } \\
\text { liberdade? }\end{array}$ & 13 & 61,9 \\
\hline$<6$ meses & 06 & 28,6 \\
\hline 6 a 18 meses & 02 & 9,5 \\
\hline$>24$ meses & 220 abril de 2010 \\
\hline
\end{tabular}

Fonte: Pesquisa de campo realizada em 23 de março a 22 de abril de 2010.

Na Tabela 3, é possível verificar que 42,9\% dos indivíduos pertencentes à amostra tiveram como motivador de sua internação a pratica do assalto, e que outros $23,8 \%$ foram internados pelo crime de assassinato. Os dados mostram ainda que $52,4 \%$ desses indivíduos são reincidentes, e que 61,9\% ficaram internados anteriormente por até 06 meses, e 28,6\% passaram até 18 meses internados em instituições de privação de liberdade.

Quadro 4 - Experiências profissionais

\begin{tabular}{|l|l|l|}
\hline Variável & N & $\%$ \\
\hline Já trabalhou com carteira assinada? & 11 & 52,4 \\
\hline Sim & 10 & 47,6 \\
\hline Não & 04 & 19,0 \\
\hline Seu último emprego foi? & 16 & 76,2 \\
\hline Formar & 01 & 4,8 \\
\hline Informal & \multicolumn{2}{|l|}{} \\
\hline Nunca trabalhou & \multicolumn{2}{|l|}{} \\
\hline $\begin{array}{l}\text { Exercia alguma atividade laborativa no momento em } \\
\text { instituição? }\end{array}$ & 11 & 52,4 \\
\hline Sim & 10 & 47,6 \\
\hline Não &
\end{tabular}

\footnotetext{
${ }^{5}$ Porte ilegal de armas, estupro e tentativa de homicídio.
} 


\begin{tabular}{|l|l|l|}
\hline Já fez algum curso técnico? & 05 & 23,8 \\
\hline Sim & 16 & 76,2 \\
\hline Não & & \\
\hline
\end{tabular}

Fonte: Pesquisa de campo realizada em 23 de março a 22 de abril de 2010.

$\mathrm{Na}$ Tabela 4, ficam expostas as experiências profissionais dos internos pertencentes a amostra. Nesta, 52,4\% dos internos já trabalhou com carteira assinada, contudo 76,2\% encontraram na informalidade seu último emprego, e ainda 52,4\% exerciam atividade laborativa no momento em que cometeu o delito. Dessa amostra $76,2 \%$ nunca participou de nenhum curso técnico.

Quadro 5 - Desejos, Perspectivas e Aspirações

\begin{tabular}{|c|c|c|}
\hline Variável & $\mathbf{N}$ & $\%$ \\
\hline \multicolumn{3}{|c|}{ Tem desejo de aprender alguma atividade profissional? } \\
\hline Sim & 21 & 100,0 \\
\hline \multicolumn{3}{|c|}{ Qual sentimento possui em relação ao futuro? } \\
\hline Esperança & 19 & 90,5 \\
\hline Incerteza & 02 & 9,5 \\
\hline \multicolumn{3}{|c|}{ Qual a perspectiva sobre o momento em que recuperar a liberdade? } \\
\hline Resgatar a autonomia & 03 & 14,3 \\
\hline Estudar & 04 & 19,0 \\
\hline Buscar profissionalização & 06 & 28,6 \\
\hline Recuperar a família & 05 & 23,8 \\
\hline Recuperar o emprego & 03 & 14,3 \\
\hline \multicolumn{3}{|c|}{ Qual sua perspectiva em 05 anos? } \\
\hline Concluir o ensino médio & 07 & 33,3 \\
\hline Aprender uma profissão & 08 & 38,1 \\
\hline Arrumar um emprego estável & 05 & 23,8 \\
\hline Mesma situação que hoje & 01 & 4,8 \\
\hline \multicolumn{3}{|c|}{ Qual sua perspectiva em 10 anos? } \\
\hline Concluir o ensino superior & 06 & 28,6 \\
\hline Aprender uma profissão & 02 & 9,5 \\
\hline Arrumar um emprego estável & 12 & 57,1 \\
\hline
\end{tabular}




\begin{tabular}{|l|l|l|}
\hline Situação pior que hoje & 01 & 4,8 \\
\hline
\end{tabular}

Fonte: Pesquisa de campo realizada em 23 de março a 22 de abril de 2010.

Na Tabela 5, todos os entrevistados (100\% da amostra), desejam aprender alguma atividade profissional, e 90,5\% possuem sentimento de esperança com relação ao futuro. Com relação às perspectivas sobre o momento em que recuperar a liberdade, $28,8 \%$ buscarão profissionalização. $\mathrm{Na}$ amostra, 38,1\% veem o aprendizado de uma profissão como perspectiva para os próximos 05 anos, e 57,1\% veem um emprego estável como objetivo para os próximos 10 anos.

Quadro 6 - Apoio Institucional

\begin{tabular}{|l|l|l|}
\hline Variável & N & $\%$ \\
\hline $\begin{array}{l}\text { Já participou de algum programa ocupacional }{ }^{6} \text { enquanto esteve internado no } \\
\text { Instituto Juiz Melo Matos? }\end{array}$ & 12 & 57,1 \\
\hline Sim & 09 & 42,9 \\
\hline Não & \multicolumn{2}{|l|}{} \\
\hline $\begin{array}{l}\text { Gostaria de participar de algum curso profissionalizante enquanto for paciente no } \\
\text { Instituto Juiz Melo Matos? }\end{array}$ & 21 & 100,0 \\
\hline Sim & \multicolumn{2}{|l|}{} \\
\hline $\begin{array}{l}\text { Qual o principal problema enfrentado por você enquanto interno do Instituto Juiz } \\
\text { Melo Matos? }\end{array}$ & 06 & 28,6 \\
\hline Ociosidade & 04 & 19,0 \\
\hline Solidão & \\
\hline
\end{tabular}

${ }^{6}$ O termo "programa ocupacional" em questão refere-se aos programas constituídos a partir das Terapias Ocupacionais. A terapia ocupacional é uma profissão da área da saúde que, diante da ampliação do conceito de saúde - entendido como o completo estado de bem-estar biopsicossocial, e não somente como a ausência de doença - estendeu seu campo de ação, abrangendo práticas sociais, através do uso de atividades, visando a promoção da saúde e a (re)inserção social de indivíduos excluídos por problemas físicos, mentais ou sociais de forma integral e independente (CAMPOS; PANÚNCIO-PINTO, 2005). Buscando, de Galheigo (2003), favorecer a organização do coletivo, a fim de possibilitar a construção da cidadania plena. Compreendendo a cidadania de acordo com a concepção de Moreira e Queiroz (2005), de que essa privilegia a perspectiva dos sujeitos, ultrapassando a noção jurídica dos direitos consagrados em lei, supondo, portanto, a intervenção dos indivíduos na conquista do que consideram direitos. Galheigo (2003), afirma que a prática da Terapia Ocupacional social é voltada à população, cujas necessidades são consequências de suas condições de exclusão do acesso aos bens sociais e que têm sua problemática manifestada pelo agravamento das condições de vida a que está submetida. Considerando-se que o adolescente infracionou devido a sua condição de exclusão e que a privação de liberdade se configura como agravamento em suas condições de vida, é possível situar o adolescente em conflito com a lei institucionalizado como sujeito alvo das ações da Terapia Ocupacional no campo social. 


\begin{tabular}{|l|l|l|}
\hline Abandono por parte da família & 02 & 9,5 \\
\hline Incertezas & 03 & 14,3 \\
\hline Outros & 06 & 28,6 \\
\hline
\end{tabular}

Fonte: Pesquisa de campo realizada em 23 de março a 22 de abril de 2010.

$\mathrm{Na}$ Tabela 6, no tocante ao apoio institucional, os internos entrevistados (57,1\%) já participaram de programas ocupacionais durante o período de internação. Quanto ao desejo de participar de cursos profissionalizantes, $100 \%$ dos internos demonstraram interesse. Na pesquisa verificou-se ainda que 28,6 dos internos identificam a ociosidade como principal problema enfrentado por eles dentro da instituição.

No intuito de ratificar as informações, obtidas através das entrevistas com os menores, realizou-se outra entrevista com os funcionários do CASE que trabalham diretamente com os internos. Para a obtenção desses dados, utilizou-se a entrevista semiestruturada para coleta de dados primários junto aos funcionários. A seguir apresentam-se as falas ${ }^{7}$ dos entrevistados a partir do seguinte questionamento.

Você identifica mudanças no comportamento do menor interno do Instituto Juiz Melo Matos durante ou após o período em que ele participa de oficinas profissionalizantes? Quais?

Sim. Muitos deles se identificam e gostam das atividades que participam. Expressam desejo de darem continuidade após serem liberados. Já ouvi muitos deles dizerem que lá fora não terão oportunidades de darem continuidade porque o contexto não permite. (ENT 01$)^{8}$.

Sim. Após algum tempo na unidade, o educando demonstra, desejo de mudar de atitude, concentram-se melhor com o passar do tempo, percebemos momentos de reflexão e expressão de preocupação em relação ao futuro. (ENT 02).

Sim. Só não sei descrever. (ENT 03).

$\mathrm{Sim}$. Na maioria das vezes o educando evidencia através de suas falas em que expressa seu desejo de mudança, isso se manifesta mais quando sentem-se psicologicamente abalados decorrente do fato da privação de liberdade. Porém muito pouco na prática, pois não conseguem vivenciar o que tem aprendido, em relação a bom comportamento e conduta digna em função da influência do meio que acaba sufocando a ânsia por mudanças efetivas em suas vidas. (ENT 04).

Sim. Durante as oficinas os alunos demonstram interesses nas atividades propostas, a conduta dos adolescentes diante dos orientadores, professores e colegas é de cordialidade, fazendo das rodas de conversa extra-atividades estejam também ligadas às atividades que desempenham durante as oficinas, a conduta do adolescente após o período da oficina não temos como informar,

\footnotetext{
${ }^{7}$ No processo de transcrição das falas, foi mantida a redação sem interferência ou correções de qualquer natureza.

${ }^{8}$ Os entrevistados serão identificados pelas siglas ENT, abreviação da palavra entrevista, seguida do numero cuja ordem correspondeu a mesma ordem das entrevistas. Ex.: (ENT 01)
} 
pois, não temos contato com os adolescentes. Após a saída do adolescente da unidade não sabemos se ele continua a desempenhar as atividades profissionalizantes. (ENT 05).

Entre os funcionários entrevistados, pode-se notar um consenso acerca da necessidade de substituição do ócio dos menores pelo aprendizado de uma atividade profissional, e como o desenvolvimento de oficinas profissionalizantes oferece para o menor uma postura reflexiva a respeito do seu futuro. Mesmo nos depoimentos, nos quais os funcionários não souberam se expressar na transcrição das respostas, o fizeram de forma oral, chamando a atenção para a positiva mudança ás vezes temporária, que a personalidade dos menores sofre quando estão desenvolvendo essas atividades.

Apesar das dificuldades enfrentadas, cem por cento dos internos têm esperança de um futuro melhor e veem na profissionalização o suporte para essa esperança, desejam aprender uma atividade profissional que possa lhes transportar para uma realidade diferente da vivida por eles atualmente, em cada resposta fica evidenciado o desejo deles, de que a reclusão seja uma situação transitória, visto que todos têm vontade de participar de cursos profissionalizantes enquanto estiverem internados no instituto, pois compreendem a importância de terem uma profissão, e veem a ociosidade com fator que anda na contramão da sua tão desejada reinserção social. Muitos deles tiveram a oportunidade de trabalhar com carteira assinada, contudo, por não possuírem capacitação, não puderam se manter num emprego formal que pudesse lhe render segurança e benefícios legais, restando a eles a incerteza, as péssimas condições de trabalho e os baixos salários de um emprego informal.

Em sua maioria possuem família nuclear, entretanto, os pilares, nos quais essa estrutura está firmada, devem ser revistos, pois não tem conseguido transmitir aos seus filhos critérios morais que os mantenham distante da criminalidade, ao contrário, tem favorecido a formação de indivíduos de caráter fraco e suscetível à prática de atos danosos à sociedade. Essas são família que beiram a subsistência, no tocante a renda, portanto a falta de riqueza não deve ser fator determinante para a violência, mesmo sendo histórico que pobreza e criminalidade possuem uma estreita relação.

Ao analisarmos determinantes à reclusão, os fatores sociais sem dúvida despontam em grande maioria como causa e efeito, contudo a reincidência e seus aspectos devem ser vistos com cautela, pois a maioria dos menores internados já passou por essa ou outra instituição de privação de liberdade, demonstrando assim a ineficiência do sistema que em tese se propõe a recuperar e ressocializar, mas que na prática funciona 
apenas como segregador que produz mais reincidentes do que recuperados. Na pesquisa, ainda foi possível constatar a presença de internos maiores de 18 anos numa instituição que deveria abrigar apenas menores, com base na pesquisa documental é possível afirmar também que esta não é uma prática rara. A incidência desses "internos" maiores de 18 anos ocorre em função do problema discutido anteriormente, "o que fazer com esse egresso", que em sua maioria não possui residência, profissão ou qualquer vínculo familiar. Equivocadamente o poder público e as instituições que deliberam a este respeito veem esse período "extra" de permanência como uma "janela de adaptação", entretanto quando o menor é internado, sua liberdade é uma certeza, geralmente com data marcada e por isso sua condição de egresso, de cidadão com direitos e deveres sociais deve ser pensada e construída desde sua entrada e não no momento de sua saída como tem ocorrido na prática.

\section{CONCLUSÃO}

A presente pesquisa traz a profissionalização se não como única, mas como principal forma de possibilitar ao menor tanto na condição de interno quanto na condição de egresso a construção de um novo projeto de vida, e o resgate dos valores perdidos, com perspectivas reais de reinserção de forma lícita no convívio social. O projeto busca ratificar hipóteses e discutir questões; configurar-se como parte ou ingrediente de uma prática múltipla que vai se consolidando, a participação acadêmica na discussão de problemas sociais, evoluindo no caminho desejado dia após dia, configurando-se assim sem formato definitivo, em processo contínuo de elaboração de medidas eficazes para a promoção gradativa de mudanças sociais.

\footnotetext{
Enquanto o assunto permanecer assunto, não se iniciou a investigação propriamente dita. $\mathrm{O}$ assunto escolhido será questionado, portanto, pela mente do pesquisador, que o transformará em problema, mediante seu esforço de reflexão, sua curiosidade ou talvez seu gênio. (CERVO; BERVIAN, 1974, p. 77).
}

Sobre os direitos de cidadania, pertencentes a todo indivíduo, o procurador de Justiça do Estado de São Paulo, Paulo Afonso Garrido de Paula, entende que:

A cidadania reclama atendimento aos interesses protegidos pela lei, porquanto, como direitos fundamentais, são essenciais para o desenvolvimento da pessoa humana e manutenção da própria dignidade. (...) Cidadão é aquele que participa da divisão da riqueza da cidade, da Nação, podendo atender às suas 
necessidades básicas e vitais, sem as quais não vive, não se desenvolve e nem atualiza suas potencialidades. (GARRIDO, 2010, p. 94).

Exceto os portadores de algum tipo de deficiência física ou mental, cabendo a cada uma delas uma discussão diferenciada, todos independente da classe social a qual pertença tem capacidades e potencialidades semelhantes, o que diferencia aqueles que conseguem obter êxito dos demais, são as oportunidades que muitas vezes lhes são possibilitadas ou usurpadas, baseadas em uma jurisprudência que peca ao imprimir uma legalidade de direitos igualitários, tratando todos como pares, quando na verdade deveria imprimir uma efetiva justiça social, tratando os iguais como iguais, e os diferentes como diferentes, promovendo verdadeiro senso de isonomia.

Através da profissionalização e de atividades laborativas, bem como o acompanhamento ao egresso na busca da redução significativa dos índices de reincidência desses internos e ainda a sua inserção/reinserção pacífica no ciclo social, utilizando como instrumento, as mais diversas práticas profissionais.

Faz-se pouco eficaz falar de justiça, enquanto as diferenças e as discrepâncias de possibilidades não forem minimizadas. Foucault (2009) entende que a igualdade dos sujeitos na ordenação jurídica, garantida pela Constituição, não significa que estes devam ser tratados de maneira idêntica pelas normas constitucionais e infraconstitucionais. A igualdade assim entendida não é concebível: seria absurdo impor a todos os indivíduos exatamente as mesmas obrigações ou lhes conferir exatamente os mesmos direitos sem fazer distinção alguma entre eles, como, por exemplo, entre crianças e adultos, indivíduos mentalmente sadios e alienados, homens e mulheres. Internos e não internos; detentos e não detentos; egressos e não egressos.

A privação de liberdade não deve ser empregada ou mesmo aceita como uma punição sem propósito ou com o propósito apenas de devolver o dano causado, “o essencial da pena (...) não creiais que consista em punir; o essencial é procurar corrigir, reeducar, "curar" [...]" (Foucault, 2009), bem como não é dado a ela o direito de segregar, a reclusão que aparta o indivíduo como meio de proteger a sociedade é uma prática que deve ser abominada. Sobre o valor moral que possui a liberdade e o direito de defesa desta, assevera Rudolf Von Thering.

A conservação da existência é a suprema lei da criação animada, por quanto ela se manifesta instintivamente em todas as criaturas; porém a vida material não constitui toda a vida do homem; tem ainda que defender sua existência 
moral que tem por condição necessária o direito: é, pois, a condição de tal existência que ele possui e defende com o direito.

O homem sem direito desce ao nível dos brutos, assim os Romanos não faziam mais do que deduzir uma lógica consequência desta ideia, quando colocavam os escravos, considerada sob o ponto de vista do direito abstrato, ao nível do animal.

Temos, pois, o dever de defender nosso direito, porque nossa existência moral está direta e essencialmente ligada à sua conservação; desistir completamente da defesa, o que atualmente não é muito prático, porém que poderia ter lugar, equivaleria a um suicídio moral. (IHERING, 2001, p.48).

Deve-se recuperar ao invés de segregar, proteger ao invés de punir, concederlhe mecanismos que o possibilite sonhar, sonhar em realizar um futuro melhor e principalmente dar-lhes a possibilidade de sonhar a concretização de um futuro possível, este deve ser o objetivo de toda instituição de privação de liberdade.

Ainda sobre segregação, podemos citar a criação das favelas, aglomerados de pessoas de baixa renda que, se para alguns lhe parece criação espontânea, não o são; funcionam como o quarto de despejo das cidades, como dizia Maria Carolina (1960). As sociedades foram calcadas sobre uma natureza ideológica de separação, desegregação, na qual se convive com o incômodo de estar em pleno século XXI, presenciando cotidiana e silenciosamente grandes médios e pequenos e desejados e planejados apartheids sociais. A sociedade quer acreditar que não há motivo para se preocupar, que aquele que não se enquadrar será recolhido, separado do convívio social, não oferecendo risco para a população, contudo, os indícios de que esta crença é negligente e equivocada está em cada esquina, assaltando e traficando, batendo nas portas, mas principalmente aromando-as e furtando, maculando todo o seu conteúdo, enquanto prostitui e macula toda a sociedade, a sociedade encontra-se agora na posição de vítima, vitimada por seu próprio descaso, os senhores são algozes de se mesmo, os senhores são fabricantes, produtores de uma calamidade social.

Que nossos centros de privação de liberdade não sejam quartos de despejo, mas sim centros de recuperação e ressocialização do indivíduo para enfim reintegrá-lo a sociedade, possibilitando a liberdade não apenas do corpo, mas desse estigma ininterrupto de reclusão e violência psicológica, bem como afinar-se também com as demandas sociais e as orientações legais que ancoradas na Lei de Diretrizes e Bases da Educação Nacional (1996), afirma que: 
Art. 39. A educação profissional e tecnológica, no cumprimento dos objetivos da educação nacional, integra-se aos diferentes níveis e modalidades de educação e às dimensões do trabalho, da ciência e da tecnologia. (Lei $n^{\circ}$ 11.741, de 2008).

$\S 1^{\circ}$ Os cursos de educação profissional e tecnológica poderão ser organizados por eixos tecnológicos, possibilitando a construção de diferentes itinerários formativos, observadas as normas do respectivo sistema e nível de ensino. (Incluído pela Lei n ${ }^{\circ} 11.741$, de 2008).

Dois pontos devem ser considerados: o primeiro é relacionado aos desejos dos internos explicitados frente à equipe técnica que entrevista e elabora o parecer; o segundo ponto a ser considerado é a demanda do mercado de trabalho que sabidamente exige capacitação na busca de mão-de-obra, que deve ser qualificada para estar apta à atende-lo, esses devem ser os balizadores no momento da escolha de quais atividades devem ser ensinadas aos internos.

É preciso não esconder sob a poeira do cotidiano que a pena deve vir acompanhada com a necessidade de ressocializar, pois se pensarmos as prisões apenas como instrumento de apartamento, depósitos de pessoas, é certo que o indivíduo mesmo após cumprir a pena, continuará inapto a conviver em sociedade, o fim educativo das penas que surgiu na Holanda do século XVI, hoje ainda não consegue conter a criminalidade, nem reabilitar o preso.

\footnotetext{
Vale ressaltar a dupla importância da prática da educação no sistema penitenciário, cumprindo duas finalidades importantes para a sociedade: evitar a ociosidade nos presídios, que segundo estudos e observações práticas geram maior propensão à especialização do crime e a propensão à reincidência, e dar ao condenado a oportunidade de, em futura liberdade, estar preparado para o exercício de uma atividade profissional para o qual seja exigido o mínimo de escolarização, permitir sua reintegração ao meio social de forma mais digna através da própria aceitação e a não rejeição pela sociedade, além de permitirlhe contribuir com seu trabalho produtivo e valoroso e ter como consequência uma remuneração pelo seu esforço, proporcionando-lhe o próprio sustento e a manutenção de sua família. (TOCANTINS, 2005, p. 22).
}

Ainda para Focault (2009, p. 258), "vamos admitir que a lei se destine a definir infrações, que o aparelho penal tenha como função reduzi-las e que a prisão seja o instrumento dessa repressão;temos então que passar um atestado de fracasso", pois o sistema como é colocado, não ressocializa, nem recupera o recluso, apenas pune cerceando o seu direito a liberdade, é urgente a necessidade de uma reforma no sistema de reclusão em especial para os menores que teoricamente possuem uma possibilidade maior de ressocialização, pois se entende que o seu caráter ainda está em processo de 
transformação possibilitando uma intervenção efetiva por parte de medidas educativas ou laborativas, lembrando sempre que a possibilidade de desenvolver atividades laborativas é sempre uma possibilidade e nunca uma imposição, pois esta feriria princípios do nosso direito e transformaria a reclusão num suplício ainda maior, este deve entender o centro de privação de liberdade como um lugar que torna possível a sua passagem da marginalidade a reintegração social, esta possibilidade visa desenvolver as aptidões, talentos e capacidades dos menores, incentivando-os a superar os seus medos e fortalecer suas crenças na estrutura social.

As prisões estão devolvendo a sociedade tudo aquilo que foi negligenciado ao indivíduo, seja ele interno, sentenciado, ou egresso, denotando a necessidade de intervenção urgente, seja na discussão e resolução da problemática dos menores desocupados, dos menores infratores, dos detentos, dos egressos e de tantas outras questões, onde fica evidente a necessidade de intervir, provocando mudanças efetivas no sistema em uso, possibilitando a reinserção do indivíduo que se sente marginalizado.

Após o delito cometido e o ato julgado inflacionário, cabe ao Estado criar para esse sentenciado não apenas deveres, mas também perspectivas que lhes deem o direito de sonhar um futuro fora do delito, um futuro possível, cabendo à sociedade assumir junto com o governo a sua parcela de responsabilidade pelo destino dos indivíduos, que se bem o olharmos, nada mais são que frutos de suas mazelas.

\title{
TORT, DETENTION AND INCARCERATION - LEARNING OF A LABOR ACTIVITY AS AN INSTRUMENT OF RESOCIALIZATION OF MINORS IN SERVING SOCIO-EDUCATIONAL MEASURES
}

\author{
Marta Cruz Machado
}

\begin{abstract}
This paper will discuss the rehabilitation of minors serving social and educational measures, CASE's internals - Institute Judge Melo Matos in Feira de Santana, by learning a productive working or professional activity. The house of socio-educational assistance Judge Melo Matos is a public institution maintained by FUNDAC/BA (State of Bahia's Foundation for Children and Teens) entity responsible for formulating and implementing a uniform policy for the protection of the rights of children and teenagers. In seeking to ratify or disprove the hypothesis, there will be an extensive study of the theoretical framework that verse on the subject, and a search through the application questionnaire
\end{abstract}


to internal, tracing the profile of this individual as well, their status in practice offense then be analyzed predisposition to learning a work activity and their desire to resocialization. It will also be a questionnaire to employees of the institute who will give his impressions of the internal moments in the development of these activities. Finally, it will be conducted with reading, processing and analysis of collected data.

Keywords: Minor offender. Melo Matos. Rehabilitation of minors. Educational measures. Professionalization.

\section{REFERÊNCIAS}

BASAGLIA, Franco. O homem no pelourinho. Educação e Sociedade, São Paulo, n 25: 73-95. dez. 1986.

BRASIL. Constituição da República Federativa do Brasil. Brasília. DF: Senado, 1988.

- Lei n ${ }^{\circ} 8.069$ de 13 de julho de 1990.Estatuto da Criança e do Adolescente. Brasília. Diário Oficial. Imprensa Nacional, 3. Disponível em: <http://www.planalto.gov.br/ccivil/LEIS/L8069.htm>.Acesso em: 19 jan. 2016, ás $01 \mathrm{~h}$ e $30 \mathrm{~min}$.

Lei no 9.394, de 20 de dezembro de 1996. Estabelece as Diretrizes e Bases da Educação Nacional. Artigos 208, inciso V - título 5, capítulo II, seção I, art. 22 a 28.Disponível em: <http:// www.educacaoonline.pro.br>. Acesso em: 23 jan. 2016, ás $23 \mathrm{~h}$ e $40 \mathrm{~min}$.

CAMPOS, F. R. S.; PANÚNCIO-PINTO, M. P. Compreendendo o significado da privação de liberdade para adolescentes institucionalizados. In: Simpósio Internacional do Adolescente. An. $1,2005.2$ Disponível em: $<\mathrm{http}$ //www.proceedings.scielo.br/scielo.php?pid=msc0000000082005000200014\&script =sci_arttext $>$ Acesso em 05jun. 2016.CERVO, Amado Luiz; BERVIAN, Pedro Alcino.Metodologia Cientifica. McGraw-Hill, 3. ed. 1983.

COMISSÃO NACIONAL DE DIREITOS HUMANOS. Revista Virtual de Direitos Humanos.Disponível em: $<$ http://www.oab.org.br/comissoes/cndh/revista02.pdf $>$.Acesso em: 25 jan. 2016, ás $06 \mathrm{~h}$ e $09 \mathrm{~min}$.

FOUCAULT, Michel. Microfísica do Poder. Rio de Janeiro: Graal, 1979.

Vigiar e Punir. História da violência nas prisões, 36. ed. Petrópolis:

Vozes, 2009.

FREIRE, P. Educação como prática para liberdade. Rio de Janeiro: Paz e Terra, 1983. 
GALHEIGO, S. M. O social: idas e vindas de um campo de ação em terapia ocupacional. In: PÁDUA, E. M. M.; MAGALHÃES, L. V. (orgs). Terapia ocupacional: teoria e prática. São Paulo: Papirus, 2003b. p. 29-46

IHERING, Rudolf von. Trad: CRETELLA JÚNIOR J. \& CRETELLA Agnes. A Luta pelo Direito. 2. ed. São Paulo: Revista dos Tribunais, 2001.

KELSEN, Hans. Teoria Pura do Direito. Traduzido por João Baptista Machado. 8.ed. São Paulo: Martins Fontes, 2009.

MAZZOTTA, Marcos José da Silveira. Educação especial no Brasil: história e políticas públicas.São Paulo: Editora Cortez, 1996.

MELLO, Celso Antônio Bandeira. O conteúdo jurídico do princípio da igualdade. 3. ed. São Paulo: Malheiros, 1999. 48 p. , p.11.

MOREIRA, E. M.; QUEIROZ, T. C. N. Juventude e cultura em com unidades precarizadas: a difícil construção da cidadania. In: ALVIM, R.; QUEIROZ, T.; FERREIRA JÚNIOR, E. (orgs.). Jovens e juventude. João Pessoa: Editora Universitária - PPGS/UFPB, 2005. p. 51-64.

PAULA, Paulo Afonso Garrido de. Política de entendimento ao adolescente infrator CEDCA/MG.

RIBEIRO, B. de M.A função de reintegração social da pena privativa de liberdade. Porto Alegre: Sergio Antonio Fabris, 2008.

SASSAKI, R.K. Inclusão: construindo uma sociedade para todos. Rio de Janeiro: WVA, 1997.

TOCANTINS. Projeto de Ressocialização Educativa na Casa de Custódia de Palmas. Palmas, TO: Secretaria de Estado da Educação e Cultura, 2005.

TRIOLA, Mario F. Introdução á Estatística. 7. ed. Rio de Janeiro: LTC, 1999.

UNICEF. Situação da infância brasileira 2001. Disponível em: $<$ http://www.unicef.org/brazil/pt/resources_10334>. Acesso em: 21 jan. 2016, ás 03h e $18 \mathrm{~min}$.

VASCONCELOS, C.T.J. de; Araújo, F.P. De e Pôrto Jr., G. Ensino diferenciado: didática e práticas pedagógicas em educação de adultos. Palmas, TO: Secretaria de Educação do Estado do Tocantins / Gerência de Educação de Jovens e Adultos, 2006. 